\title{
Using electronic surveying to assess psychological distress within the UK university student population: a multi-site pilot investigation
}

\author{
Bridgette M Bewick (b.m.bewick@ leeds.ac.uk) \\ Academic Unit of Psychiatry and Behavioural Sciences, Leeds Institute of Health Sciences, University of Leeds, 101 \\ Clarendon Road, Leeds, LS2 9LJ, UK \\ Jan Gill (JGill@qmu.ac.uk) \\ Subject Area of Nursing, Queen Margaret University, Edinburgh, UK \\ Brendan Mulhern (B.J.Mulhern@leeds.ac.uk) \\ Academic Unit of Psychiatry and Behavioural Sciences, Leeds Institute of Health Sciences, University of Leeds, 101 \\ Clarendon Road, Leeds, LS2 9LJ, UK
}

Michael Barkham (M.Barkham@ @ sheffield.ac.uk)

Centre for Psychological Services Research, University of Sheffield, Western Bank, S10 2TP, Sheffield, UK

Andrew J Hill (A.J.hill@ leeds.ac.uk)

Academic Unit of Psychiatry and Behavioural Sciences, Leeds Institute of Health Sciences, University of Leeds, 101 Clarendon Road, Leeds, LS2 9LJ, UK

\begin{abstract}
This paper describes the level of psychological distress within university students participating in an evaluation of a web-based intervention for alcohol use. Data was collected from 1129 students from four UK universities. Psychological distress was assessed using an online version of the CORE-10. Results showed that $29 \%$ of students reported clinical levels of psychological distress. Eight percent of students had moderate-to-severe or severe levels of distress. The items tapping depression and anxiety suggest that, when compared to depression scores, levels of anxiety are heightened. These findings are discussed in light of the evidence which suggests that traditional modes of support delivery may not be sufficient for all students. The possibility that webbased therapeutic interventions could be utilized within this highly computer literate population is explored.
\end{abstract}

Keywords: student; psychological well-being; mental health; web-based intervention; e-health; CORE-10

\section{Introduction}

Internationally there is an enduring interest in the mental health of university students, with studies from around the world reporting heightened levels of psychological distress within the student population (e.g., Everly et al., 1994; Henry, 1986; Nagayama , Aikawa \& Matsunaga, 1972). Recent changes in UK higher education, namely the abolition of student grants in favour of student loans and the introduction of tuition fees, have resulted in students' lives becoming increasingly pressurised. These changes have meant that the lives of students are different in many ways to that experienced by students 20 or 30 years ago (Association for University and College Counselling (AUUC), 1999; Royal College of Psychiatrists (RCP), 2006). As a result there have increasingly been calls to better understand the psychological well-being of university students both in the US (Bertocci, Hirsch, Sommer \& Williams, 1992; Hayes, 1997) and the UK (Grant, 2002; Grant \& Wolfson, 2001; Humphrey \& McCarthy, 1998; Monk \& Mahmood, 1999; Roberts, Golding, Towell \& Weinreb, 1999).

Within the UK there is now the expectation that $50 \%$ of young people will attend higher education by 2010 (Court, 2004). Some have expressed concern that this widening participation agenda may result in higher levels of psychological distress within the student population (RCP, 2006); especially given the evidence that students from nontraditional backgrounds, who have been disadvantaged in many respects, may require greater support in order to cope with the stresses of being a student (AUUC, 1999).

Where research has compared the well-being of students to that of the general population, university students generally fare worse on measures of psychological well-being (e.g., Roberts \& Zelenyanski, 2002; Roberts et al., 1999; Stewart-Brown et al., 2000). Some studies of student mental health have focused on identifying causes of stress for students while others have tried to discover the relationship between these and mental health. Academic, relationship and financial difficulties have been found to be some of the major causes of stress for university students (Grant, 2002) and relationships between these variables and mental health have also been found (e.g., Andrews \& Wilding, 2004; Monk, 2004; Roberts \& Zelenyanski, 2002). From previous studies it appears that between $22 \%$ and $54 \%$ 

university student population: a multi-site pilot investigation

of the university student population report heightened levels of psychological distress (Webb, Ashton, Kelly \& Kamali, 1996; Andrews \& Wilding, 2004; Cooke et al., 2006). There is also evidence from single university samples within the UK that the period spent at university is an anxious rather than depressive time (Andrews \& Wilding, 2004; Cooke et al., 2006).

Previous UK studies have suggested that levels of anxiety may be higher in female students when compared to their male peers (Cooke et al., 2006; Webb et al., 1996). In addition it appears that psychological distress increases with time across the degree course (Andrews \& Wilding, 2004; Cooke et al., 2006).

The majority of the current UK research has used the traditional pen and paper survey approach within a single university population. A notable exception is the work of Webb et al. (1996) who included 3075 second year students from 10 universities; unfortunately the results did not discuss institutional differences. According to ratings on the Hospital Anxiety and Depression Scale (HADS; Zigmond \& Snaith, 1983), students reported higher levels of anxiety $(54 \%)$ when compared to depression (13\%). However it is possible that the psychological stressors experienced by students have altered considerably over the last decade and it is not clear if these changes have resulted in changes to student psychological well-being, nor is it clear if levels of psychological distress differ across institutions.

Over the past decade there has been an increasing development in the area of IT, particularly web-based procedures in the field of assessment and self-help. The use of such health technologies may be ideally suited to university students. Hence, our aim in the present study was to evaluate the feasibility of using a web-based mode of delivery to assess the level of psychological distress within university students participating in an evaluation of a webbased intervention for alcohol use.

\section{Method}

\section{Participants}

A sample of 2284 university students who registered to take part in an evaluation of a web-based intervention for student alcohol use were asked to complete a preintervention survey that included a measure of psychological well-being. Students were recruited to the larger study via campus-wide student emails. The recruitment process emphasised that both consumers and non-consumers of alcohol were required to take part. Fortynine percent $(n=1129)$ of students responded. The distribution of sensible, harmful and hazardous drinking behaviour within the sample was similar to that reported by studies that have investigated alcohol consumption within the general student population (e.g., Bewick et al., 2008a). Students were drawn from four universities across the UK.
Several universities agreed to participate only if they were not identified; hence none are named. Each university contributed the following number of participants: Institution $1 \mathrm{n}=580$ (51\%); Institution $2 \mathrm{n}=365$ (33\%); Institution $3 \mathrm{n}=103$ (9\%); Institution $4 \mathrm{n}=76(7 \%)$. Seventyfour percent were female $(n=832), 88 \% \quad(n=985)$ were White/White British, 94\% $(n=1058)$ were undergraduate students. The mean age was $21.4(\mathrm{SD}=5.1)$ with an age range between 17 and 58 years. The study was approved by Leeds East NHS Research Ethics Committee.

\section{Materials}

The questions detailed were part of a wider survey investigating student alcohol consumption however only the items of relevance to the current paper are discussed here. Students were asked to complete the Clinical Outcomes in Routine Evaluation ten item measure ( CORE-10) (Connell \& Barkham, 2007), a short-form of the Clinical Outcomes in Routine Evaluation Outcome Measure CORE-OM (Barkham et al. 2001, 2005; Evans et al. 2002). The CORE10 comprises 10 items relating to the domains of symptoms (anxiety, depression, physical and trauma), life functioning and risk to self. The psychometric properties of the CORE10 have shown it to have good internal reliability with an alpha for the overall scale of 0.82 (CI 0.79-0.85) (Connell \& Barkham, 2007). To be a reliable measure of psychological distress at least nine of the ten items must be completed. All items were scored from 0 ('not at all') to 4 ('all the time') and item scores were totaled and divided by the number of items completed yielding a mean item score of between 0 and 4. Paralleling procedures in reporting findings using the CORE-OM, CORE-10 mean score was multiplied by 10 yielding a score from 0 to 40 and referred to as a student's clinical score (Leach et al., 2006); providing participants answer all ten items this procedure is equivalent to adding up all individual item scores. Lower clinical scores indicate better mental health. A clinical score of above 10 is indicative of heightened psychological distress. The following CORE-10 clinical score cut points were applied: $<6.2$ healthy, $6.2>\& \leq 10$ low levels of distress, $10>\&<15$ mild severity, $15 \geq \&<20$ moderate severity, $20 \geq \&<24.7$ moderate-to-severe, $\geq 24.7$ severe (Connell \& Barkham, 2007; Barkham, et al. 2006). Within the current sample the values of Cronbach's Alpha were 0.82 for the clinical score and 0.81 and 0.68 for depression ( 2 items) and anxiety (2 items) respectively.

\section{Procedure}

The electronic survey was designed using the Bristol Online Survey system (2007). Students who had registered to take part in the project were contacted by email via their university during the autumn semester of the 2007/08 academic year. The email included a url link that enabled students to access the survey using the Internet. After 
receiving the email students had four weeks to complete the survey. Two reminder emails were sent to students during the four weeks. For participating in the wider study students were entered into an institutional prize draw to win one of four $£ 25$ Amazon gift certificates.

\section{Results}

The mean CORE-10 clinical score was $8.02(\mathrm{SD}=6.09)$. When scores were coded according to level of psychological distress $46 \%(n=520)$ scored within the 'healthy' range and a further $25 \%(n=282)$ of students had low levels of distress and were therefore also within the non-clinical range. Twenty-nine percent $(n=327)$ of students had raised CORE10 clinical scores (i.e., clinical score $>10$ ). This included $8 \%$ $(n=88)$ students who had moderate-to-severe or severe levels of distress (see Table 1). graduate status (i.e., undergraduate or postgraduate) $(\mathrm{F}(2$, $1115)=0.98, \quad \mathrm{p}>0.05 ; \quad \mathrm{F}(2, \quad 1115)=0.67, \quad \mathrm{p}>0.05 ; \quad \mathrm{F}(2$, $1115)=0.24, \quad \mathrm{p}>0.05)$; university institution $(\mathrm{F}(3$, 1114) $=0.82, \quad \mathrm{p}>0.05 ; \quad \mathrm{F}(3, \quad 1114)=0.82, \quad \mathrm{p}>0.05 ; \quad \mathrm{F}(3$, $1114)=1.48, \quad \mathrm{p}>0.05)$ or year of study within the undergraduate sample $(\mathrm{F}(2,1052)=0.18, \mathrm{p}>0.05 ; \mathrm{F}(2$, $1052)=0.74, \mathrm{p}>0.05 ; \mathrm{F}(2,1052)=1.28, \mathrm{p}>0.05)$.

\section{Discussion}

Approximately one in three university students who participated in the current study reported heightened levels of psychological distress. This figure is within the range reported previously $(66 \%>8$ Anxiety HAD Andrews and Wilding, 2004; 23\% above GP-CORE cut-off Cooke et al., 2006; 54\% >8 Anxiety HAD Webb et al., 1996). That $8 \%$ of students are reporting moderate-to-severe or severe levels of distress is notable. Given reports that traditional services (e.g., referral to counselling) may not be sufficient for some

Table 1 CORE-10 Clinical Scores for the male, the female, and the overall sample

\begin{tabular}{|c|c|c|c|c|c|c|}
\hline & \multicolumn{2}{|c|}{$\begin{array}{c}\text { Male } \\
n=292\end{array}$} & \multicolumn{2}{|c|}{$\begin{array}{c}\text { Female } \\
n=832\end{array}$} & \multicolumn{2}{|c|}{$\begin{array}{l}\text { Overall } \\
n=1729\end{array}$} \\
\hline & $M$ & $(S D)$ & $M$ & $(S D)$ & $M$ & $(S D)$ \\
\hline \multicolumn{7}{|l|}{ CORE-10 scores } \\
\hline CORE-10 Clinical Score (10 items) & 8.02 & $(6.09)$ & 8.63 & $(6.50)$ & 8.47 & $(6.41)$ \\
\hline Depression (2 items) & 7.74 & $(8.42)$ & 9.01 & $(9.29)$ & 8.70 & $(9.12)$ \\
\hline \multirow[t]{2}{*}{ Anxiety ( 2 items) } & 8.36 & $(8.38)$ & 9.54 & $(9.16)$ & 9.25 & $(9.01)$ \\
\hline & $N$ & (\%) & $N$ & (\%) & $N$ & (\%) \\
\hline \multicolumn{7}{|l|}{$\begin{array}{l}\text { Level of psychological distress } \\
\text { Non-clinical ronge }\end{array}$} \\
\hline Healthy & 147 & $(50.3)$ & 369 & $(44.4)$ & 520 & (46.1) \\
\hline Low & 70 & $(24.0)$ & 212 & $(25.5)$ & 282 & (25.0) \\
\hline \multicolumn{7}{|l|}{ Clmic al range } \\
\hline Mild & 26 & (8.9) & 107 & $(12.9)$ & 133 & (11.8) \\
\hline Moderate & 32 & (11.0) & 74 & $(8.9)$ & 106 & $(9.4)$ \\
\hline Moderate-to-severe & 13 & $(4.5)$ & 45 & (5.4) & 58 & $(5.1)$ \\
\hline Severe & 4 & (1.4) & 25 & $(3.0)$ & 30 & $(2.7)$ \\
\hline
\end{tabular}

Paired t-tests revealed significantly higher anxiety compared to depression scores within the overall sample $(t(1123)=2.644, p<0.01)$. Once split by sex this difference remained for females $(\mathrm{t}(826)=2.16, \mathrm{p}<0.05)$ but was not significant for males $(\mathrm{p}>0.05)$.

Scores on depression differed significantly between male and female students $(\mathrm{F}(1,1116)=1.92, \mathrm{p}<0.05)$. No significant differences in clinical score $(\mathrm{F}(1,1116)=1.92$, $\mathrm{p}>0.05)$ or anxiety $(\mathrm{F}(1,1116)=3.71, \mathrm{p}>0.05)$ were found between the sexes.

No significant differences in clinical score, depression or anxiety were found between students with differing: students (Brandon \& Payne, 2002), future research would benefit from investigating if these students are receiving the support they require to enable them to successfully complete their degree course.

Unlike previous studies the current results found no difference in levels of anxiety between the sexes. Additionally, levels of psychological distress were comparable across the undergraduate degree course and no institutional differences were found. Since the current study was not powered specifically to test for between degree course or institutional differences these results should be 
interpreted with caution but they do warrant further investigation.

Despite differing methodologies across studies, this is the third UK study to have found higher levels of anxiety when compared to depression. While recent developments in the UK have meant that UK University students now have a signposted online resource for depression (i.e., Students Against Depression, 2007), work to develop a comprehensive cross-university online resource for student levels of anxiety appears to be lagging. The Internet has provided a promising avenue for delivering brief interventions to students (e.g., Bewick et al., 2008b) and recent advances in computerized Cognitive Behavioural Therapy (CBT) suggest that web-based interventions are effective for treating depression and anxiety (Spek et al., 2007). Given the willingness of students to respond to online surveys and to engage with brief web-based interventions (Richards \& Tangney, 2007) this could be a useful way to moderate the levels of anxiety within the student population.

The current investigation suggests that students are prepared to answer questions about their psychological wellbeing electronically. That $49 \%$ of students sampled responded to the survey is encouraging; however there is a need for further understanding of who participates in online surveys and how we can best minimise non-responders within a student population. The current study did include a small incentive (in the form of a prize draw) but it may be that students would respond better to a different form of incentive and/or a greater chance of 'winning'.

A number of limitations should be acknowledged. The current study included only students who were taking part in a study investigating the effectiveness of a web-based intervention for student alcohol use and therefore we do not know if the mental health of these students differs from students who choose not to participate in the evaluation. In addition, the study included a high proportion of females (74\%) and therefore the representativeness of the sample would have to be ascertained before extrapolating the results to the wider student population. The current study used the CORE-10 as a measure of psychological distress, the measure was designed both as a screening tool for psychological distress and also as an outcome measure for the psychological therapies. Therefore while the current results provide an indication of possible levels of anxiety and depression within the student population, future studies would benefit from including standardized measures of anxiety and depression (e.g., PHQ-9, GAD-7) in order to more accurately, and comprehensively assess these dimensions within this population.

\section{Conclusions}

That a third of participants from across four UK universities had raised levels of psychological distress is of concern. Perhaps more importantly almost 1 in 10 students were scoring within the moderate to severe range. Given this, there is a need to ensure that students are able to access the services and support they require in order to successfully graduate from their degree course. The Internet offers an innovative and potentially cost effective way of providing tailored resources and support to students. The majority of university students are highly computer literate and seemingly willing to engage with web-based material therefore internet delivered therapeutic interventions should be explored as a means of providing support within this population.

\section{Acknowledgements}

We thank Student Executive members and University staff at each of the universities for their input into the project. We would also like to thank all the participants who gave their time to be involved in this project. This project was partially funded by the Alcohol Education Research Council (AERC).

\section{References}

Andrews, B \& Wilding J.M. (2004). The relation of depression and anxiety to life-stress and achievement in students. British Journal of Psychology, 95, 509-521.

Association for University and College Counselling (AUUC). (1999). Degrees of Disturbance: The New Agenda. Rugby: BACP.

Barkham, M., Mellor-Clark, J., Connell, J \& Cahill, J. (2006). A core approach to practice-based evidence: A brief history of the origins and applications of the CORE-OM and CORE system. Counselling and Psychotherapy Research, 6, 3-15.

Barkham, M., Margison, F., Leach, C., Lucock, M., MellorClark, J., Evans, C. \& McGrath, G. (2001). Service profiling and outcomes benchmarking using the COREOM: Towards practice-based evidence in the psychological therapies. Journal of Consulting and Clinical Psychology, 69, 184-196.

Barkham, M., Gilbert, N., Connell, J., Marshall, C. \& Twigg, E. (2005). Suitability and utility of the CORE$\mathrm{OM}$ and CORE-A for assessing severity of presenting problems in psychological therapy services based in primary and secondary care settings. British Journal of Psychiatry, 186, 239-246.

Bertocci, D, Hirsch, E., Sommer, W. \& Williams, A. (1992). Student mental health needs: survey results and implications for service. Journal of American College Health , 41, 3-12.

Bewick, B.M., Mulhern, B., Barkham, M. Trusler, K., Hill, A.J. and Stiles, W.B. (2008a). Changes in undergraduate student alcohol consumption as they 
progress through university. BMC Public Health, 8, 163.

Bewick, B.M. Trusler, K., Mulhern, B., Barkham \& Hill, A.J. (2008b). Feasibility and effectiveness of a webbased personalized feedback and social norms alcohol intervention in UK university students: a randomized control trial. Addictive Behaviors, Doi:10.1016/j.addbeh.2008.05.002.

Brandon, D. \& Payne, J. (2002). Breakdown. In Stanley, N. \& Manthorpe, J. (Eds). Students' Mental Health Needs Problems and Responses. London, Jessica Kinsley.

Bristol Online Survey (BOS, 2007). Unviersity of Bristol. http;//www.survey.bris.ac.uk.

Connell, J. \& Barkham, M. (2007). CORE-10 User Manual, Version 1.1. CORE System Trust and CORE Information Management Systems Ltd.

Cooke, R., Bewick, B.M., Barkham, M., Bradley, M. \& Audin, K. (2006). Measuring, monitoring and managing the psychological well-being of first year university students. British Journal of Guidance and Counselling, 34, 505-518.

Court, S. (2004). Government getting closer: Higher Education and Devolution in the UK. Higher Education Quarterly, 58, 151-175.

Evans, C., Connell, J., Barkham, M., Margison, F., MellorClark, J.,McGrath, G., Mellor-Clark, J. Audin, K. (2002). Towards a standardised brief outcome measure: Psychometric properties and utility of the CORE-OM. British Journal of Psychiatry, 180, 51-60.

Everly, J.S., Poff, D.W., Lamport, N., Hamant, C. \& Alvey, G. (1994). Perceived stress and coping strategies of occupational therapy students. American Journal of Occupational Therapy, 48, 1022-1028.

Grant, A. (2002). Identifying students' concerns taking a whole institutional approach. In: Stanley, N. \& Manthorpe, J (Eds), Students' Mental Health Needs Problems and Responses. London: Jessica Kinsley.

Grant, A. \& Wolfson, M. (2001). Responding to students in difficulty: a cross institutional collaboration. $A U U C$ Newsletter and Journal, 1, 9-11.

Hayes, J.A. (1997). What does the Brief Symptom Inventory measure in college and university counseling center clients? Journal of Counseling Psychology, 44, 360-367.

Henry, P. (1986). Role of psychological services in college environment. Journal of College Student Psychotherapy, 1, 43-51.

Humphrey, R. \& McCarthy, P. Stress and the contemporary student. Higher Education Quarterly, 52, 221-242.

Leach, C., Lucock, M. Barkham, M., Stiles, W.B., Noble, R. \& Iveson, S. (2006). Transforming between Beck Depression Inventory and CORE-OM scores in routine clinical practice. British Journal of Clinical Psychology, 45, 153-166.

Monk, E. Student mental health. Part 2: the main study and reflections of significant issues. Counselling Psychology Quarterly, 17, 33-43.

Monk, E.M. \& Mahmood, Z. (1999). Student mental health: a pilot study. Counselling Psychology Quarterly, 12, 199-210.

Nagayama, H., Aikawa, K. \& Matsunaga, F. (1972). Mental disorders among university students studied through doctors' interviews. Kuyushu Neuro-Psychiatry, 18I, 201-205.

Richards, D. \& Tangney, B. (2007). An informal online learning community for student mental health at university: a preliminary investigation. British Journal of Guidance and Counselling, 36, 81-97.

Roberts, R., Golding, J., Towell, T. \& Weinreb, I (1999). The effects of economic circumstances on British students' mental and physical health. Journal of American College Health , 48, 103-109.

Roberts, R. \& Zelenyanski, C. (2002). Degrees of debt. In: Stankley, N. \& Manthorpe, J. (Eds), Students' Mental Health Needs Problems and Responses . London: Jessica Kinsley.

Royal College of Psychiatrists (RCP). (2006). The Mental Health of Students in Higher Education . London: RCP.

Spek, V., Cuijpers, P., Nyklicek, I., Riper, H., Keyzer, J. Pop, V. (2007). Internet-based cognitive behaviour therapy for symptoms of depression and anxiety: a meta-analysis. Psychological Medicine, 37, 319-328.

Stewart-Brown, S., Evans, J., Patterson, J., Peterson, S., Doll, H., Balding, J. \& Regis, D. (2000). The health of students in institutes of higher education: an important and neglected public health problem? Journal of Public Health Medicine , 22, 492-499.

Students Against Depression. (2007). http://www.studentsdepression.org. Charlie Waller Memorial Trust.

Webb, E., Ashton, C.H., Kelly, P. \& Kamali, F. (1996). Alcohol and drug use in UK university students. The Lancet, 348, 922-925.

Zigmond, A.S., and Snaith, R.P. (1983). The Hospital Anxiety and Depression Scale. Acta Psychiatrica Scandinavica, 67, 361-370.

Correspondence to: Bridgette M Bewick, Leeds Institute of Health Sciences, University of Leeds, Charles Thackrah Building, 101 Clarendon Road, Leeds, LS2 9LJ, UK. b.m.bewick@leeds.ac.uk 